\title{
Is travel actually risky? A study of situational causes of victimization
}

\author{
Stijn Ruiter ${ }^{1,2^{*}}$ (1) and Wim Bernasco $1,3+$
}

\begin{abstract}
Objective: We present a first test using a smartphone time use survey app for whether the risk of criminal victimization is higher while traveling than during other activities, and assess risk heterogeneity between public transport, private transport by car, and private open-air transport.

Methods: A sample of 1334 young adults completed a time-use survey on their smartphones with additional items on criminal victimization. Participants reported their time use and victimization experiences (vandalism, theft, threat, or assault) per 10-min timeslot for 4 days. To prevent potential confounders from affecting the results, we analyzed the data with a fixed effects logit model that exclusively relies on within-person variation between timeslots.

Findings: A total of 78 victimization situations were reported by 45 participants. Although these numbers are too low to draw definitive conclusions, with respect to the four types of victimization measured, sleeping appeared to be the safest activity. The risk of victimization was considerably larger during travel, but also during many other activities. We found shopping to be the activity with the highest risk of victimization. No victimization was observed during private transport by car, but the risk of victimization was significantly higher in private open-air and public transport than during sleep.

Conclusion: Using a state-of-the-art instrument and a rigorous statistical design, we tentatively conclude that the risk of criminal victimization is not higher during travel than during most other activities, only sleeping is safer. Larger samples are needed to assess the robustness of our findings. We discuss practical implications, strengths and weaknesses of the study, and new research challenges.
\end{abstract}

Keywords: Victimization risk, Time use, Travel mode, Smartphone, Fixed effects

\section{Background}

Travel has been associated with a heightened risk of criminal victimization (Lemieux and Felson 2012; Levine and Wachs 1986a; Newton and Ceccato 2015). If fear of crime deters people from traveling, it limits their economic and civic participation and represents considerable societal costs. This paper presents the results of a first smartphone time use survey aimed at assessing whether claims of heightened victimization risk during travel are justified.

*Correspondence: ruiter@nscr.nl; s.ruiter@uu.n

† Stijn Ruiter and Wim Bernasco contributed equally to this study

${ }^{1}$ Netherlands Institute for the Study of Crime and Law Enforcement

(NSCR), PO Box 71304, 1008 BH Amsterdam, The Netherlands

Full list of author information is available at the end of the article
The two main theories of victimization are routine activity theory (Cohen and Felson 1979) and lifestyle theory (Hindelang et al. 1978). Both theories postulate that criminal victimization is a function of the activities that potential victims engage in and the settings that they are exposed to, and both theories share a focus on proximate causes of victimization. Proximate causes are those events that occur close in space and time to victimization. In other words, both theories emphasize the situational characteristics that differentiate victimization from non-victimization rather than the personal characteristics that differentiate victims from non-victims.

Neither routine activity theory nor lifestyle theory explicitly addresses the role of travel in victimization. However, both claim that exposure to potential offenders and the absence of guardians heighten the risk of 
victimization, and both risk factors seem to apply disproportionately to travel.

Travelers often find themselves amongst crowds that include potential offenders, and in unfamiliar places and situations. They are often tired or distracted and vulnerable for lack of guardianship, especially when they travel alone (Myhre and Rosso 1996). These observations appear to justify the belief that travel is a risky activity. They also suggest that it might be important to distinguish between travel modes, as travel modes may vary in terms of exposure to potential offenders and levels of guardianship.

Given the current state of knowledge, the first question we address in the present paper is whether people indeed suffer a higher risk of victimization during travel than during other activities. We answer this question with a novel approach using a dedicated smartphone survey app, which respondents used to report their time use and victimization per 10-min interval. Because travel modes vary in terms of exposure to motivated offenders and the presence of guardians, it seems likely that they also vary in terms of victimization risk. We therefore compare three general travel modes: public transport, private transport by car, and private 'open air' transport. We hypothesize that private transport by car is associated with the lowest risk of victimization because motivated offenders have almost no access to drivers and passengers inside closed private cars. Although victimization in public transport has received most attention in both scientific research (e.g., Smith and Clarke 2000) and public debate, it is actually hard to predict which of the other two travel modes is riskiest. On the one hand, public transport is in principle open to anyone, but in practice restricted to people who pay travel fares. Furthermore, in public transport there are usually guardians present who carry some responsibility for the safety of passengers, such as bus drivers, ticket inspectors, conductors, subway station attendants, and who may help prevent victimization. The level of guardianship during private 'open air' transport, on the other hand, is generally lower as nobody but police is tasked with the safety of the traveler. However, people who use private 'open air' transport also tend to be exposed to much fewer people than those who travel by public transport, as public transport usually confines many people in relatively small spaces whereas open air transport does not. Because the result of the opposing forces of guardianship and potential offenders is uncertain, it would be pure speculation to predict which of the two travel modes is riskiest.

The empirical literature provides indirect evidence for the hypothesis that the risk of victimization is heightened during travel. For example, research findings suggest that tourists are at a heightened risk of victimization
(Chesney-Lind and Lind 1986; de Albuquerque and McElroy 1999), although it is acknowledged that their heightened risk might be caused not by travel but by the risky behaviors that some tourists undertake or by their attractiveness as potentially wealthy crime targets (Boakye 2010).

Commuters-individuals who travel to and from work or school-are another mobile category. The victimization rates of work commuters tend to be higher than those of others and to be correlated with average commuting time (Messner et al. 2007; Moura and Neto 2015). The same holds true for children and adolescents who travel to school (Burrow and Apel 2008; Deakin 2006; Moore et al. 2011; Wiebe et al. 2013).

The literature is sparse on differentiation between travel modes, and public versus private transport is the main distinction made. In particular, users of public transport appear to suffer a heightened risk of victimization (Levine and Wachs 1986a, b; Messner et al. 2007; Smith and Clarke 2000; Smith and Cornish 2006; Tseloni and Pease 2003, 2004). Furthermore, crime rates are heightened around transit stations (Barnum et al. 2017; Bernasco and Block 2011; Block and Davis 1996; Ceccato and Uittenbogaard 2014; Haberman and Ratcliffe 2015; Summers and Caballero 2017), although this does not necessarily imply victimization of travelers. It may not even prove heightened risk, because crime rates in and around transit stations may be biased if their denominators do not properly account for the large ambient population of traveling persons, especially during rush hours (Andresen 2006; Gerell 2018; Song et al. 2018).

The above findings, however, are not at all conclusive about the proximate causes of victimization. Neither heightened victimization risk of tourists and commuters nor crime concentrations around transit stations necessarily imply that victimization risk is heightened during travel. Such a conclusion is potentially subject to an aggregation fallacy as it is about situational risk (being victimized while traveling) but the empirical evidence applies to individuals (being a victim and being a traveler). A heightened victimization risk among frequent travelers does not imply they are victimized while traveling. If travelers differ from non-travelers on attributes related to victimization risk, these confounders invalidate any conclusions about the proximate causal relation between travel and victimization.

The strongest evidence that victimization risk is heightened during travel comes from a study by Lemieux and Felson (2012). The authors combined data from the National Crime Victimization Survey (NCVS) and the American Time Use Survey (ATUS) and made use of the fact that the NCVS asked victims what activity they were involved in at the time of victimization. Accounting 
for the amount of time subgroups of the US population (based on gender, age, and ethnic background) spend on each of nine activity categories (estimated from the ATUS), they found that home activities (both sleeping and while awake) were the safest, as they had the lowest number of victimizations per hour spent. In contrast, going to and from school was associated with a much larger victimization risk than other activities. The second and third riskiest activities were commuting to or from work, and leisure activities away from home. These results were directly opposite to the conclusions when time use was not taken into account. Thus, overall more people were victimized at home than during school or work commutes, but per hour spent the reverse was true.

The study by Lemieux and Felson (2012) improves on prior research about victimization risk during travel in three ways. First, it explicitly measured victimization during travel rather than victimization in general. Second, by controlling for the average time spent traveling in the US population, it used the appropriate denominator for calculating average victimization risk. Third, it compared victimization during travel with victimization while performing other activities.

The study of Lemieux and Felson (2012) has its own limitations though, which we address in the present study. First, in contrast to those used by Lemieux and Felson (2012), our measures of activities and victimization were reported by the same individuals. This frees us from the assumption that within broad demographic categories, victims do not systematically differ from non-victims, and allows us to use a rigorous fixed effects estimator based on within-person differences across timeslots. Second, because Lemieux and Felson (2012) combined two separate datasets on violent victimization and activities, their analysis was necessarily limited to establishing the bivariate relationship between activity type and violent victimization. Our survey participants reported per 10-min timeslot not only their activities, but also the presence of relatives and friends, and substance use. This allows us to rigorously test the hypotheses using a statistical model of victimization that accounts for other variables beyond activity type. Third, whereas in the research of Lemieux and Felson (2012) travel activity was limited to travel to and from school or work (i.e. commuting), we include travel for all purposes, and differentiate between three broad travel mode categories: public transport, private transport by car, and private 'open-air' transport.

\section{Data and methods}

\section{Smartphone time use and victimization survey app}

In order to study situational correlates of victimization, we developed a dedicated time use and victimization survey smartphone app Dagboek Activiteiten en Risico [Activities and Risk Diary] for the iOS and Android platforms. The app was programmed by a company that had previously developed a similar time use survey app (Sonck and Fernee 2013). The version we designed had additional questions on victimization, on witnessing crime, and on substance use, and had greater differentiation on transport modes and on the categories of people present. The app confirms with the HETUS guidelines on harmonized European time use surveys (Eurostat 2009) in that it asks respondents to report about their activities in 10-min intervals, starts each response day at 4 a.m., and uses the overall HETUS activity categories (for more details on app design and how it follows HETUS guidelines, see Sonck and Fernee 2013). Although the app could be installed by anyone, participation in our survey required a unique login code that was sent to respondents in the invitation to participate.

\section{Sample and fieldwork}

Because victimization is a rare event, few people would report any victimization during a standard time use survey research period of 2 days, and unrealistically large samples of the general population would be required for a study like this. However, because victimization rates decline with age (Statistics Netherlands 2016), we decided to invite young adults to report about their time use and victimization experiences over a 4-day period. Our study design was approved by the Ethics Committee for Legal and Criminological Research of the Vrije Universiteit Amsterdam. We invited a sample of 2675 participants of the ongoing Children of Immigrants Longitudinal Survey in the Netherlands (Jaspers and Van Tubergen 2015) panel study for which we had a valid email address or postal address. The panel study had originally started with a random sample of children of immigrants and their native peers in the Netherlands at the age of around 14 in the year 2010.

Invitation letters and emails explained the purpose of the study and contained unique login codes for each participant. The invitation also explained the progressive remuneration scheme in which we would send respondents a 40-euro gift card if they completed the full 4 days of the time use survey, a 20-euro gift card for those who would miss 1 day, a 10-euro gift card for 2 days, and respondents who participated less than 2 days would not receive a gift card. The unique login codes corresponded with a randomly assigned set of four fieldwork days in two consecutive weeks in the period September 28 to October 11, 2015. All those who had not yet logged into the app for the first time at the start of data collection were sent a reminder email, which included two additional fieldwork days. From returned invitation letters 
and bounced emails we learned that 17 people never received the invitation. About $50 \%$ of the remaining 2658 participated in our study $(\mathrm{N}=1334)$.

A complete fieldwork day yielded 144 unique records per respondent ( $24 \mathrm{~h}$ times six timeslots per hour). Given the demanding nature of the task, partial non-response was limited, as $75.5 \%$ of the respondents had at least one observation in each of the four fieldwork days, while the percentages were only $7.7 \%$ for 3 days, and 4.2 and $4.7 \%$ for 2 days and 1 day respectively. Many respondents were sent the reminder email and they thus received two additional fieldwork days. Even though they were asked to fill out the time use and victimization survey for 4 days only, 5.3 and $2.7 \%$ of the respondents actually recorded some time use data for 5 and 6 fieldwork days respectively.

\section{Situational variables}

Because the aim of this study is to assess during which situations people are more likely to get victimized, all variables in the analysis apply not to the person but to the timeslot. Victimization was measured with four questions: Was something that belongs to you vandalized? Was something that belongs to you stolen? Were you threatened? Were you hit, kicked or physically injured? These crime types were chosen based on three criteria. They had to be common forms of crime, the list of additional questions had to be limited to four in order to fit within an already labor-intensive 4-day time use survey design, and the types of crime had not to be too sensitive because that would potentially lead to dropout. Respondents who reported victimization during a fieldwork day were asked to indicate during which timeslot they had been victimized. After the first two questions, they could also indicate that victimization had happened earlier but was only noticed afterwards. If this was the case, these victimizations were discarded, so that only victimization incidents during a specified timeslot were used in the analysis. In sum, 45 respondents (3.37\% of all individuals) reported at least one form of victimization during 78 distinct timeslots, including 30 vandalism incidents, 3 thefts, 24 cases of threat, and 30 assaults. These partially overlapping incidents were combined into a single binary victimization variable. In terms of risk, the victimization rate is .67 victimizations per 1000 person-hours (see Table 2).

The smartphone app asked respondents to select one out of a list of 48 predefined categories of activities for each timeslot of a fieldwork day. Respondents could also select the Other activity category and define the activity themselves. We coded all activities into the following nine mutually exclusive categories: Public transport, Private transport by car, Private open-air transport, Work, Education, Shopping/errands, Leisure, Sleeping, and
Other activity. Table 1 presents the full list of activity categories and the coding scheme. With regard to transportation, some specific features of the Dutch transportation system should be emphasized. First, in comparison to most other countries in the world, bicycles are omnipresent and heavily used both in urban and rural environments. Therefore, besides walking and riding a scooter, cycling is the main travel mode covered in the category "private open-air transport". Second, public transportation is well-developed and heavily used, with trains, trams and buses serving most of the country on a regular basis. Finally, and specifically relevant for the age group in the sample, the age at which people are allowed to drive a car without a coach is 18 .

Respondents were also asked to indicate which other people were present in a situation. For each timeslot, they used tick boxes to select whether they were alone, with their partner, with children under the age of 10 , with other household members, with friends/peers, or with someone else they knew. We used this information to create three dichotomous variables. Friends present scores 1 for all timeslots during which friends/peers were present and 0 otherwise. Partner or household member present scores 1 when either the respondent's partner or a household member was present and 0 otherwise. Children present scores 1 for all situations for which respondents indicated children were present and 0 otherwise. Note that these dummy variables are not mutually exclusive as different people could have been present in a situation.

Substance use was recorded by asking respondents whether they had used alcohol, cannabis or party drugs during a fieldwork day and if so, during which particular timeslots. All time use measurements were also categorized into four 6-h intervals to capture the time of day: 6 a.m.-noon, noon-6 p.m., 6 p.m.-midnight, and midnight -6 a.m.

\section{Methods}

To statistically test the situational effects on victimization, we estimated a fixed effects logit model using the 25,613 unique timeslots of the 45 victims in the sample. This model allows us to rigorously test the within-person effects of a change in the independent variables on the likelihood of getting victimized, while accounting for all measured and unmeasured time-invariant between-person heterogeneity. In other words, a fixed effects model calculates the model parameters by comparing only repeated observations of the same individual. This procedure assures that the estimates are not confounded by differences between individuals, and it therefore provides a more rigorous test of situational explanations than the alternative random effects model, which derives the 
Table 1 Activity coding scheme

\begin{tabular}{|c|c|c|}
\hline Main activity categories in app & Subcategories & Activity coding \\
\hline Sleeping & & Sleeping \\
\hline \multirow[t]{2}{*}{ Eating and drinking } & Eating and drinking at home, work or school & Other \\
\hline & Going out for eating and drinking & Leisure \\
\hline Personal or medical care & & Other \\
\hline Employment & & Work \\
\hline \multirow[t]{2}{*}{ Study/education } & School, university & Education \\
\hline & Study, course as a hobby & Education \\
\hline \multirow[t]{5}{*}{ Domestic work } & Cooking/food preparation & Other \\
\hline & Household upkeep, cleaning & Other \\
\hline & Gardening and taking care of pets & Other \\
\hline & DIY, construction and repairs & Other \\
\hline & Administration/paper work & Other \\
\hline \multirow[t]{2}{*}{ Shopping and services } & Shopping/groceries & Shopping/errands \\
\hline & Services & Shopping/errands \\
\hline \multirow[t]{3}{*}{ Caring for/helping children and adults } & Caring and supervising children (of own family) & Other \\
\hline & Helping other adults within own family & Other \\
\hline & Helping others outside the family & Other \\
\hline \multirow[t]{3}{*}{ Social contacts } & Visits/having visitors, parties & Leisure \\
\hline & Having a talk & Leisure \\
\hline & Using the telephone & Leisure \\
\hline \multirow[t]{3}{*}{ Television, radio, reading } & Watching television & Leisure \\
\hline & Listening to radio and music & Leisure \\
\hline & Reading & Leisure \\
\hline \multirow[t]{5}{*}{ Computer and internet } & Gathering information and news via the internet & Leisure \\
\hline & Online banking and online shopping & Shopping/errands \\
\hline & Communicating through the internet (online) & Leisure \\
\hline & Other pc/internet offline & Leisure \\
\hline & Computer games & Leisure \\
\hline \multirow[t]{10}{*}{ (Other) leisure } & Voluntary work & Work \\
\hline & Sports & Leisure \\
\hline & Visiting sports/competitions & Leisure \\
\hline & Going out, cultural visits & Leisure \\
\hline & Library & Leisure \\
\hline & Trips & Leisure \\
\hline & Hobby & Leisure \\
\hline & Playing games & Leisure \\
\hline & Resting & Leisure \\
\hline & Religious and ceremonial activities & Leisure \\
\hline \multirow[t]{9}{*}{ Traveling } & Walking & Private transport open-air \\
\hline & Cycling & Private transport open-air \\
\hline & Moped/scooter & Private transport open-air \\
\hline & Own car & Private transport by car \\
\hline & Taxi & Private transport by car \\
\hline & Bus & Public transport \\
\hline & Tram & Public transport \\
\hline & Train & Public transport \\
\hline & Other mode of transportation & Other \\
\hline Registering time use by the smartphone & & Other \\
\hline
\end{tabular}


Table 2 Bivariate relations between victimization and situational factors per 10-min timeslot

\begin{tabular}{|c|c|c|c|c|c|c|c|}
\hline & \multicolumn{4}{|c|}{ All respondents } & \multicolumn{3}{|c|}{ Victims only } \\
\hline & $v$ & $\#$ & $\%$ & $\lambda$ & $\#$ & $\%$ & $\lambda$ \\
\hline \multicolumn{8}{|l|}{ Activity } \\
\hline Public transport & 3 & 14,229 & 2.03 & 1.27 & 594 & 2.32 & 30.30 \\
\hline Private transport by car & 0 & 10,226 & 1.46 & .00 & 371 & 1.45 & .00 \\
\hline Private transport open-air & 2 & 17,649 & 2.51 & .68 & 553 & 2.16 & 21.70 \\
\hline Work & 11 & 51,843 & 7.38 & 1.27 & 2172 & 8.48 & 30.39 \\
\hline Education & 7 & 87,300 & 12.43 & .48 & 2988 & 11.67 & 14.06 \\
\hline Shopping/errands & 6 & 9996 & 1.42 & 3.60 & 355 & 1.39 & 101.41 \\
\hline Leisure & 37 & 154,142 & 21.95 & 1.44 & 5612 & 21.91 & 39.56 \\
\hline Sleeping & 4 & 274,587 & 39.10 & .09 & 10,150 & 39.63 & 2.36 \\
\hline Other activity & 8 & 82,320 & 11.72 & .58 & 2818 & 11.00 & 17.03 \\
\hline \multicolumn{8}{|l|}{ Time of day } \\
\hline 6 a.m.-noon & 15 & 179,447 & 25.55 & .50 & 6563 & 25.62 & 13.71 \\
\hline Noon-6 p.m. & 20 & 176,643 & 25.15 & .68 & 6495 & 25.36 & 18.48 \\
\hline 6 p.m.-midnight & 22 & 173,002 & 24.63 & .76 & 6326 & 24.70 & 20.87 \\
\hline Midnight-6 a.m. & 21 & 173,200 & 24.66 & .73 & 6229 & 24.32 & 20.23 \\
\hline \multicolumn{8}{|l|}{ Substance use } \\
\hline No & 55 & 690,138 & 98.27 & .48 & 25,018 & 97.68 & 13.19 \\
\hline Yes & 23 & 12,154 & 1.73 & 11.35 & 595 & 2.32 & 231.93 \\
\hline \multicolumn{8}{|l|}{ Friends present } \\
\hline No & 37 & 578,312 & 82.35 & .38 & 20,457 & 79.87 & 10.85 \\
\hline Yes & 41 & 123,980 & 17.65 & 1.98 & 5156 & 20.13 & 47.71 \\
\hline \multicolumn{8}{|c|}{ Partner or household member present } \\
\hline No & 59 & 567,403 & 80.79 & .62 & 20,767 & 81.08 & 17.05 \\
\hline Yes & 19 & 134,889 & 19.21 & .85 & 4846 & 18.92 & 23.52 \\
\hline \multicolumn{8}{|l|}{ Children present } \\
\hline No & 77 & 695,968 & 99.10 & .66 & 25,418 & 99.24 & 18.18 \\
\hline Yes & 1 & 6324 & .90 & .95 & 195 & .76 & 30.77 \\
\hline Total sample & 78 & 702,292 & & 67 & 25,613 & & 18.27 \\
\hline
\end{tabular}

Absolute number of victimizations $(v)$, number of 10 -min timeslots (\#), percentages (\%), and number of victimizations per $1000 \mathrm{~h}(\lambda)$

model parameters from comparisons between observations of the same person and observations of different persons, and which relies on the unjustified assumption that there are no relevant unobserved differences between individuals.

The limited number of victimizations and the very strong association between victimization and activity type created (quasi-)complete separation in the model. Therefore, we followed the approach of Averdijk and Bernasco (2015) and estimated the model using a penalized maximum likelihood estimation technique. Quasicomplete separation happens when a combination of independent variables perfectly predicts the outcome variable, which often happens when logit models are estimated with binary or nominal independent variables on small or sparse data sets. Standard maximum likelihood estimation techniques would yield infinite model parameters and standard errors, whereas penalized maximum likelihood estimation reduces this small sample bias and actually outperforms alternative methods of handling quasi-complete separation in logit models. Because the likelihood function of the fixed effects logit model is equivalent to that of the Cox proportional hazard model, we estimated our model with penalized likelihood maximization using the coxphf package (Heinze and Ploner 2016) developed for the statistical programming language R (R Core Team 2017). Results are presented as odds ratios $\left(\mathrm{e}^{\mathrm{b}}\right)$, which reflect the factor by which the odds of victimization are deflated or inflated with a oneunit change in the independent variable controlling for all other covariates.

\section{Results}

Before we turn to the statistical test of situational factors related to victimization risk, Table 2 displays the distribution of all independent situational variables as well as 
their relationships with victimization across all 10-min timeslots. The table includes a wealth of information that is too comprehensive to discuss in detail. To assist interpretation, we discuss the presence of friends as an example. The first column shows that we distinguish between situations with and without friends. The second column $(v)$ shows that 41 victimization incidents occurred in situations with friends and 37 in situations without friends. The third and fourth column (\# and \%) show that 123,980 timeslots $(17.65 \%)$ were spent with friends and $578,312(82.35 \%)$ without friends. Using these figures, the expected number of victimizations for $1000 \mathrm{~h}$ spent $(\lambda)$ with friends can be calculated by dividing the 41 victimization incidents by 123,980 timeslots and subsequently multiplying that by 6 (the number of 10-min timeslots in an hour) and by 1000, which results in an average of 1.98 victimizations per $1000 \mathrm{~h}$ spent with friends, whereas the same calculation yields .38 victimizations per $1000 \mathrm{~h}$ spent without friends.

The rightmost three columns (\#, $\%$ and $\lambda$ ) apply to victims only. They show that victims spent somewhat more time with friends $(20.1 \%)$ than the average respondent (17.7\%), and that their risk of victimization was larger (47.71 victimization per $1000 \mathrm{~h}$ spent) in the presence of friends than when these were absent (10.85 victimization per $1000 \mathrm{~h}$ spent). The bivariate relationships presented in Table 2 further show that the risk of victimization was relatively high in situations with substance use and when people traveled with public transport, or when they were at work, were engaged in shopping or errands, and were involved in leisure activities. Note that no victimization at all was reported during travel by car.

The results of the fixed effects logit model presented in Table 3 show that sleeping (the reference category with odds ratio fixed to 1 ) is the safest activity, as all other odds ratios are higher than 1 . The risk of criminal victimization is indeed larger during travel than during sleep. However, all other activities also have a higher risk of victimization than sleeping. In fact, shopping is the riskiest activity $(\mathrm{OR}=108.541 ; \mathrm{p}<.001)$. Even though we observed no victimization during private transport by car (see Table 2), the penalized estimation technique estimates the odds ratio to be 4.290 , but the estimate is not statistically significant and thus we cannot conclude that the risk of criminal victimization is larger when traveling by car than while sleeping. However, victimization risk is significantly higher in private open-air $(\mathrm{OR}=26.676$; $\mathrm{p}<.001)$ and in public transport $(\mathrm{OR}=27.576$; $\mathrm{p}<.001)$ than during sleeping. Both modes of transport do not statistically differ in their respective risks of victimization (see Appendix A: Table 4). We also tested travel (by any mode of transportation) against all other activities, but the results revealed no statistically significant differences
Table 3 Multivariate fixed effects (firth-type penalized likelihood) estimates of relation between victimization and situational elements (odds ratios)

\begin{tabular}{lc}
\hline Activity (sleeping= ref.) & \\
Public transport & $27.576^{* * *}$ \\
Private transport by car & 4.290 \\
Private transport open-air & $26.676^{* *}$ \\
Work & $35.861^{* * *}$ \\
Education & $8.507^{* *}$ \\
Shopping/errands & $108.541^{* * *}$ \\
Leisure & $11.682^{* * *}$ \\
Other activity & $10.987^{* * *}$ \\
Time of day (midnight-6 a.m. =ref.) & .438 \\
6 a.m.-noon & $.246^{* *}$ \\
Noon-6 p.m. & $.333^{* *}$ \\
6 p.m.-midnight & $14.314^{* * *}$ \\
Substance use & $1.864^{*}$ \\
Friends present & 1.122 \\
Partner or household member present & 1.487 \\
Children present & \\
\hline
\end{tabular}

${ }^{*} \mathrm{p}<.05,{ }^{* *} \mathrm{p}<.01,{ }^{* * *} \mathrm{p}<.001$ (two-tailed)

in the likelihood of victimization. Thus, travel is only riskier than sleeping but not riskier than other activities. People also run a relatively high risk of victimization while working $(\mathrm{OR}=35.861 ; \mathrm{p}<.001)$ and the next safest to sleeping turns out to be activities related to education $(\mathrm{OR}=8.507 ; \mathrm{p}<.01)$. Because Table 3 only presents ORs for activities tested against sleeping as reference category, Appendix A: Table 4 presents Wald Chi square tests to assess which effects differed statistically significantly. Working seems to be more risky than education-related, leisure and other activities; shopping/errands more than education-related, leisure, travel by private car and other activities.

The parameter estimates of the control variables in Table 3 are also important. Substance use increases the odds of victimization by a factor $14.3(\mathrm{p}<.001)$, whereas situations with friends are almost twice as risky as those without $(\mathrm{OR}=1.864 ; \mathrm{p}<.05)$. The riskiest time of day is between midnight and 6 a.m., and all other hours show reduced odds of victimization, although the effects are only statistically significant for noon to 6 p.m. $(\mathrm{OR}=.246$; $\mathrm{p}<.01)$ and 6 p.m. to midnight $(\mathrm{OR}=.333$; $\mathrm{p}<.01)$. The presence of partners or household members or children does not affect the risk of victimization.

\section{Conclusion and discussion}

\section{Summary}

This study demonstrated that it is possible to use a custom-made smartphone app to investigate situational 
causes of victimization. The research question addressed two propositions: (1) that victimization risk is elevated during travel, and (2) that travel mode further differentiates victimization risk. In contrast to prevailing claims in the literature, our results suggest that travel is not riskier than other activities, except for sleeping. We distinguished between three modes of transport (private car, open air private, and public transport). Private open-air transport and public transport appeared to be equally risky, while transportation by private car seems to immunize against victimization. These conclusions should be considered tentative because of the relatively small sample size in combination with the rarity of experiencing victimization and the limitation of the observation period to just 4 days.

\section{Practical implications}

Based on our findings, concerns about elevated risk of victimization during travel seem premature. Public transportation appears equally risky as private open-air transportation, and both activities are not riskier than other activities, such as working, learning, shopping or leisure.

While the findings are still tentative and not sufficiently robust to be practically applied, in the future, knowledge about situational causes of victimization may be used in apps that inform their users about the safety level of the situations they are about to enter. These tools may help people to be extra vigilant at the right time and place, and could even issue warnings in extremely risky situations. They could be used in a similar way as local weather forecasting services, as an automated tool for obtaining useful information that could help people avoid unpleasant experiences.

\section{Methodology for future research}

Although our method of integrating victimization in an innovative time use survey app solves some limitations of prior approaches, the method is quite resource-intensive. To obtain reliable estimates of victimization risk in specific activities, large samples of respondents need to report their activities over prolonged periods of time. Given the demanding nature of the task, a substantive remuneration may be necessary to motivate their continued participation. The space-time-budget (STB) instrument as developed by Wikström et al. (2012) also collects information on situational characteristics and crime, but does so per hour (rather than per $10 \mathrm{~min}$ ), with a much longer recall period of at least 4 days, and through an even more resource-intensive face-to-face interview. Although the STB design has been used to study situational explanations for victimization (Averdijk and
Bernasco 2015), most travel activities are relatively short and therefore underreported in the STB design.

If the main purpose of the research is calculating activity based victimization risks for a handful of population subgroups, the approach taken by Lemieux and Felson (2012) is much more efficient, because it effectively combines existing large-scale data from time use and victimization surveys, instruments that have been around for decades already.

If, however, the purpose is to develop and test a model for the proximate causes of victimization, a fine-grained measurement instrument like our smartphone survey app seems necessary. The main disadvantages of such a design are that it requires a considerable effort from the respondents and many of them do not experience any victimization during the study period and will thus be excluded from a within-person analysis. Although we do not know how retention rates would develop for longer study periods, having respondents report their activities and victimization experiences during 4 days seems about the limit of what can be asked of them even with a generous remuneration scheme. With a random sample of people, the responses of most respondents will actually be useless for estimating within-person effects and much of the data collection thus wasted. This limitation can be overcome by starting from a sample of victims and using a time-matched control design to study how the actual victimization event differs from all situations leading up to the event (see Basta et al. 2010; Wiebe et al. 2013). However, such a design only works for very serious types of victimization (often with injuries), for which the hospitals could provide sample frames.

In our view, the most promising way forward is to further extend automated measurement. Currently, the app measures only time and location automatically without any user intervention. It has been demonstrated that travel mode can be automatically measured with good reliability (Bohte and Maat 2009), which means that users could be freed from answering any questions regarding their mobility. Furthermore, apps can also measure whether other devices are in close proximity by sensing their unique Bluetooth signatures, and thus derive the presence of people, and other social features of the situation (Eskes et al. 2016). In theory, such a design could even be used to capture interactions between different participants in the same study, an objective measure of convergences in time and space. Apps could also register levels of sound and lighting in the environment, or even include biological measures like heart rate, blood pressure or alcohol consumption automatically and unobtrusively, and maybe even provide valid estimates of activity 
types. Although these and other measures require considerable privacy issues to be solved in advance, their implementation would move research into the direction of complete automation of time use measurement, and require respondents only to report about any victimization experiences every once in a while (e.g., once a week).

Objective victimization risk may not be congruent with subjective safety experiences. Fear of crime may lower the comfort of travel and even keep people from traveling. In order to assess the extent to which objective and subjective safety align, future studies may include measures of both at the situational level. A recent study shows that situational variation in subjective safety experiences can also be captured using an app similar to the one used in our study (Solymosi et al. 2015).

\section{Limitations and caveats}

The relatively small number of reported victimization situations $(\mathrm{N}=78)$ in our data limits the conclusions that can be drawn from the analysis, in particular from the multivariate logit model in which we condition on no less than 15 variables. Only 45 of the 1334 respondents (3.4\%) were a victim of any of the four types of crime measured during the study period. Because these numbers do not allow for further disaggregating the analysis, the findings presented in this study reflect average effects across the four types of crimes. Larger samples are needed for assessing whether the situational factors differentially affect the risk of particular types of victimization. Nevertheless, it is worth emphasizing that the 78 victimizations reported by 1334 respondents over 4 days, imply that on average they suffer more than 5 victimizations of vandalism, theft, threat, and or assault annually. This estimate is far above the estimates in traditional victimization surveys, and may indicate that our instrument is more sensitive than traditional surveys, leading respondents to report some victimizations they would not report in traditional surveys.

The small absolute number of victimizations is also the reason why we did not explore possible interaction effects. It would be theoretically and practically relevant to know whether the effects of some factors are conditional on other factors. For example, traveling by public transport might be risky only when traveling alone and not when traveling in company. Certain activities might also be more risky at particular places or times of day, and in fact the smartphone survey app also included geotracking that in theory would allow us to reference the reported activities in space and assess whether situational factors are actually spatially dependent. For example, according to crime pattern theory (Brantingham et al. 2017), motivated offenders commit crimes at places they are familiar with. If potential victims travel to these places, they are more likely exposed to motivated offenders and thus run a higher risk of victimization. However, the number of victimizations in our data do not allow us to further disaggregate the sample. Larger samples would be needed to test how the interplay of situational factors and where and when they coexist affect victimization risk.

A limitation that our study shares with most other research on victimization is that the relevant theoretical constructs that motivate hypotheses on victimization risk are only indirectly-and thus relatively poorlymeasured. Our instrument neither measures individuals' exposure to potential offenders nor the presence of capable guardians. It measures the presence of other people in terms of their relation to the respondent (e.g., family members or friends) but not whether they are potential offenders or guardians, or maybe even both, depending the situation. Maybe shopping/errands comes out as the riskiest activity because it exposes people to relatively many motivated offenders without sufficient guardianship, but without a design that properly measures these constructs this remains speculation.

The finding that travel by car seems to make people immune to victimization while private open air and public transport are both characterized by a similar victimization risk, suggests that cars shield people from motivated offenders, which makes them safe havens. The physical protection a car provides seems to do more against victimization than the guardianship received from co-passengers, bus drivers, train personnel and other professionals in public transportation.

Not all victimization is directly related to the activities of victims. Our method and analytical strategy obviously only applies to victimization that occurs close in time and space to its presumed causes. When people are threatened over e-mail, their residences burgled in their absence, or their bicycle vandalized while parked, the victimization is only remotely related to people's activities at the time of the crime. Property crime has the distinctive feature that the target (the object illegally taken) is different form the victim (the owner of the object). In fact, owners are often the first to guard their own property, and it is their absence and inability to exercise any control (Reynald 2010) that provides opportunities for offenders. As was mentioned in our data section, we excluded victimization cases from our analysis if the victims had not been present when they were victimized and only afterwards learned about the event. 
The nature of transportation is subject to continuous change as a function of environmental challenges (e.g., use of sustainable energy sources) and technological developments (e.g., transportation by means of automated vehicles). In theorizing about the threats and opportunities of prospective developments in human mobility, effects on criminal victimization risk should be taken into account.

Authors' contributions

The listed order of authors was decided by chance. Both authors read and approved the final manuscript.

\section{Author details}

${ }^{1}$ Netherlands Institute for the Study of Crime and Law Enforcement (NSCR), PO Box 71304, 1008 BH Amsterdam, The Netherlands. ${ }^{2}$ Department of Sociology, Utrecht University, Utrecht, The Netherlands. ${ }^{3}$ Department of Spatial Economics, Vrije Universiteit Amsterdam, Amsterdam, The Netherlands.
Acknowledgements

We thank Frank van Tubergen and Eva Jaspers for allowing us to invite the respondents of their CILSNL panel study for participation in our smartphone survey.

\section{Competing interests}

The authors declare that they have no competing interests.

Availability of data and materials

Given the sensitive nature of the micro-level time-use and victimization survey data, the authors cannot share the used dataset.

Funding

Nederlandse Organisatie voor Wetenschappelijk Onderzoek (452-12-004).

\section{Appendix A}

See Table 4

Table 4 Wald Chi square test for effect size differences

\begin{tabular}{|c|c|c|c|c|c|c|c|}
\hline & Education & Shopping/errands & Leisure & Other & Public transport & $\begin{array}{l}\text { Private } \\
\text { transport } \\
\text { open-air }\end{array}$ & $\begin{array}{l}\text { Private } \\
\text { transport } \\
\text { by car }\end{array}$ \\
\hline Work & $5.689^{*}$ & 2.781 & $4.463^{*}$ & $4.193^{*}$ & .132 & .136 & 1.892 \\
\hline Education & & $15.573^{* * *}$ & .389 & .215 & 2.920 & 2.133 & .199 \\
\hline Shopping/errands & & & $16.058^{* * *}$ & $13.868^{* * *}$ & 3.234 & 2.843 & $4.327^{*}$ \\
\hline Leisure & & & & .020 & 1.837 & 1.239 & .451 \\
\hline Other & & & & & 1.850 & 1.331 & .384 \\
\hline Public transport & & & & & & .001 & 1.385 \\
\hline Private transport open-air & & & & & & & 1.258 \\
\hline
\end{tabular}

${ }^{*} \mathrm{p}<.05,{ }^{* *} \mathrm{p}<.01,{ }^{* * *} \mathrm{p}<.001$ (one-tailed) 


\section{Publisher's Note}

Springer Nature remains neutral with regard to jurisdictional claims in published maps and institutional affiliations.

Received: 25 May 2018 Accepted: 31 August 2018

Published online: 05 September 2018

\section{References}

Andresen, M. A. (2006). Crime measures and the spatial analysis of criminal activity. British Journal of Criminology, 46(2), 258-285. https://doi. org/10.1093/bjc/azi054

Averdijk, M., \& Bernasco, W. (2015). Testing the situational explanation of victimization among adolescents. Journal of Research in Crime and Delinquency, 52(2), 151-180. https://doi.org/10.1177/0022427814546197.

Barnum, J. D., Caplan, J. M., Kennedy, L. W., \& Piza, E. L. (2017). The crime kaleidoscope: A cross-jurisdictional analysis of place features and crime in three urban environments. Applied Geography, 79, 203-211. https://doi. org/10.1016/j.apgeog.2016.12.011.

Basta, L. A., Richmond, T. S., \& Wiebe, D. J. (2010). Neighborhoods, daily activities, and measuring health risks experienced in urban environments. Social Science \& Medicine, 71(11):1943-1950. https://doi.org/10.1016/j. socscimed.2010.09.008.

Bernasco, W., \& Block, R. (2011). Robberies in Chicago: A Block-level analysis of the influence of crime generators. Crime Attractors and Offender Anchor Points Journal of Research in Crime and Delinquency, 48(1), 33-57. https:// doi.org/10.1177/0022427810384135.

Block, R., \& Davis, S. (1996). The environs of rapid transit stations: A focus for street crime or just another risky place? In R. V. Clarke (Ed.), Preventing mass transit crime (Vol. Clarke, pp. 237-257). Monsey: Criminal Justice Press.

Boakye, K. A. (2010). Studying tourists' suitability as crime targets. Annals of Tourism Research, 37(3), 727-743. https://doi.org/10.1016/j.annal s. 2010.01 .002

Bohte, W., \& Maat, K. (2009). Deriving and validating trip purposes and travel modes for multi-day GPS-based travel surveys: A large-scale application in the Netherlands. Transportation Research Part C: Emerging Technologies, 17(3), 285-297. https://doi.org/10.1016/j.trc.2008.11.004.

Brantingham, P. J., Brantingham, P. L., \& Andresen, M. A. (2017). The geometry of crime and crime pattern theory. In R. Wortley \& M. Townsley (Eds.), Environmental criminology and crime analysis (pp. 98-116). New York: Routledge.

Burrow, J. D., \& Apel, R. (2008). Youth behavior, school structure, and student risk of victimization. Justice Quarterly, 25(2), 349-380. https://doi. org/10.1080/07418820802025181.

Ceccato, V., \& Uittenbogaard, A. C. (2014). Space-time dynamics of crime in transport nodes. Annals of the Association of American Geographers, 104(1), 131-150. https://doi.org/10.1080/00045608.2013.846150

Chesney-Lind, M., \& Lind, I. Y. (1986). Visitors as victims crimes against tourists in Hawaii. Annals of Tourism Research, 13(2), 167-191. https://doi. org/10.1016/0160-7383(86)90036-8.

Cohen, L. E., \& Felson, M. (1979). Social change and crime rate trends: A routine activity approach. American Sociological Review, 44, 588-608.

de Albuquerque, K., \& McElroy, J. (1999). Tourism and crime in the Caribbean. Annals of Tourism Research, 26(4), 968-984. https://doi.org/10.1016/S0160 $-7383(99) 00031-6$.

Deakin, J. (2006). Dangerous people, dangerous places: the nature and location of young people's victimisation and fear. Children and Society, 20(5), 376-390. https://doi.org/10.1111/j.1099-0860.2006.00011.x.

Eskes, P., Spruit, M., Brinkkemper, S., Vorstman, J., \& Kas, M. J. (2016). The sociability score: App-based social profiling from a healthcare perspective. Computers in Human Behavior, 59, 39-48. https://doi.org/10.1016/j. chb.2016.01.024.

Eurostat. (2009). Harmonised European time use surveys (HETUS), Guidelines 2008 (Methodologies and Working papers). Luxembourg: Office for Official Publications of the European Communities.

Gerell, M. (2018). Bus stops and violence, are risky places really risky? European Journal on Criminal Policy and Research. https://doi.org/10.1007/s1061 $0-018-9382-5$
Haberman, C. P., \& Ratcliffe, J. H. (2015). Testing for temporally differentiated relationships among potentially criminogenic places and census block street robbery counts. Criminology, 53(3), 457-483.

Heinze, G., \& Ploner, M. (2016). Coxphf: Cox Regression with Firth's Penalized Likelihood. Version 1.12. Retrieved January 8, 2018, from https://cran.r-proje ct.org/package $=$ coxphf.

Hindelang, M., Gottfredson, M. R.. \& Garafalo, J. (1978). Victims of personal crime: An empirical foundation for a theory of personal victimization. Cambridge: Ballinger.

Jaspers, E., \& Van Tubergen, F. (2015). Children of Immigrants Longitudinal Survey in the Netherlands (CILSNL) - Wave 5. Reduced version v5.0.0. DANS. https:// doi.org/10.17026/dans-x3j-bakt

Lemieux, A. M., \& Felson, M. (2012). Risk of violent crime victimization during major daily activities. Violence and Victims, 27(5), 635-655.

Levine, N., \& Wachs, M. (1986a). Bus crime in Los Angeles: I-measuring the incidence. Transportation Research Part A: General, 20(4), 273-284.

Levine, N., \&Wachs, M. (1986b). Bus crime in Los Angeles: I- —victims and public impact. Transportation research part A: general, 20(4), 285-293.

Messner, S. F., Lu, Z., Zhang, L., \& Liu, J. (2007). Risks of criminal victimization in contemporary Urban China: An application of lifestyle/routine activities theory. Justice Quarterly, 24(3), 496-522. https://doi.org/10.1080/07418 820701485429.

Moore, S., Maclean, R., \& Jefford, T. (2011). The 'land in-between': A comparative European study of the victimisation of young people travelling to and from school. Crime Prevention and Community Safety, 13(4), 246-259. https //doi.org/10.1057/cpcs.2011.12

Moura, K., \& Neto, R. S. (2015, 25-28 August 2015). Does a longer commuting time increases the probability of being victim of urban violence? The evidence from Brazilian Metropolitan Regions. Paper presented at the 55th European Regional Science Association Meeting, Lisbon, Portugal.

Myhre, M. L., \& Rosso, F. (1996). Designing for security in Météor: A projected new métro line in Paris. In R. V. Clarke (Ed.), Preventing mass transit crime (pp. 199-216). Monsey: Willow Tree Press.

Newton, A., \& Ceccato, V. (2015). Theoretical perspectives of safety and security in transit environments. In V. Ceccato \& A. Newton (Eds.), Safety and security in transit environments; an interdisciplinary approach (pp. 23-36). New York: Palgrave Macmillan.

$R$ Core Team. (2017). R: A language and environment for statistical computing. Vienna: Austria.

Reynald, D. M. (2010). Guardians on guardianship: Factors affecting the willingness to supervise, the ability to detect potential offenders, and the willingness to intervene. Journal of Research in Crime and Delinquency, 47(3), 358-390. https://doi.org/10.1177/0022427810365904.

Smith, M. J., \& Clarke, R. V. (2000). Crime and public transport. Crime and Justice, 27, 169-233. https://doi.org/10.1086/652200.

Smith, M. J., \& Cornish, D. B. (2006). Secure and tranquil travel: Preventing crime and disorder on public transport. Abingdon: Routledge.

Solymosi, R., Bowers, K., \& Fujiyama, T. (2015). Mapping fear of crime as a context-dependent everyday experience that varies in space and time. Legal and Criminological Psychology, 20(2), 193-211. https://doi. org/10.1111/lcrp.12076.

Sonck, N., \& Fernee, H. (2013). Using smartphones in survey research: A multifunctional tool. The Haque: The Netherlands Institute for Social Research.

Song, G., Liu, L., Bernasco, W., Xiao, L., Zhou, S., \& Liao, W. (2018). Testing indicators of risk populations for theft from the person across space and time: The significance of mobility and outdoor activity. Annals of the American Association of Geographers. https://doi.org/10.1080/24694452.2017.14145 80.

Statistics Netherlands. (2016). Veiligheidsmonitor 2015. Den Haag: Statistics Netherlands.

Summers, L., \& Caballero, M. (2017). Spatial conjunctive analysis of (crime) case configurations: Using Monte Carlo methods for significance testing. Applied Geography, 84, 55-63. https://doi.org/10.1016/j.apgeo g.2017.05.002.

Tseloni, A., \& Pease, K. (2003). Repeat personal victimization. 'Boosts' or 'Flags'? British Journal of Criminology, 43, 196-212.

Tseloni, A., \& Pease, K. (2004). Repeat personal victimization: Random effects, event dependence and unexplained heterogeneity. British Journal of Criminology, 44, 931-945. 
Wiebe, D. J., Guo, W., Allison, P. D., Anderson, E., Richmond, T. S., \& Branas, C. C. (2013). Fears of violence during morning travel to school. Journal of Adolescent Health, 53(1), 54-61. https://doi.org/10.1016/j.jadohealth .2013.01.023.
Wikström, P. O. H., Oberwittler, D., Treiber, K., \& Hardie, B. (2012). Breaking rules: The social and situational dynamics of young people's urban crime. Oxford: Oxford University Press.
Submit your manuscript to a SpringerOpen ${ }^{\odot}$ journal and benefit from:

- Convenient online submission

- Rigorous peer review

- Open access: articles freely available online

- High visibility within the field

- Retaining the copyright to your article

Submit your next manuscript at $\boldsymbol{\nabla}$ springeropen.com 